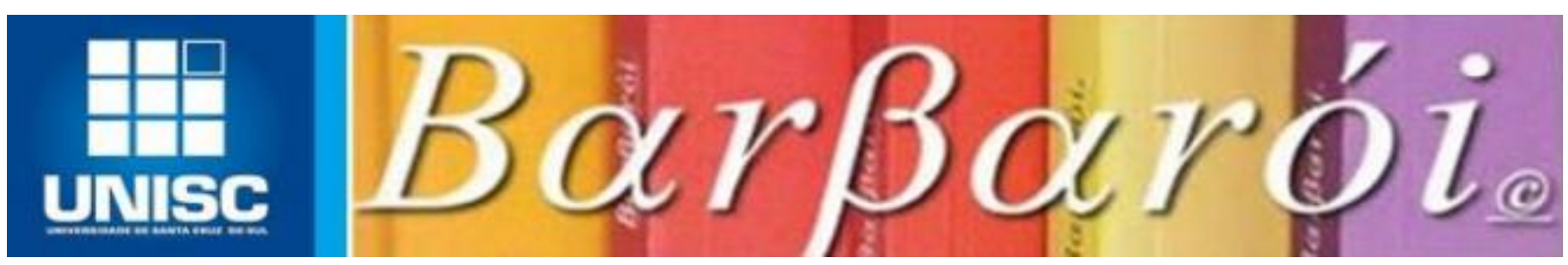

\title{
A PRODUÇÃO CIENTÍFICA BRASILEIRA SOBRE HOMENS AUTORES DE VIOLÊNCIA - REFLEXÕES A PARTIR DE UMA REVISÃO CRÍTICA DE LITERATURA
}

DOI: http://dx.doi.org/10.17058/barbaroi.v51i1.8313

\author{
Rodrigo Caio de Padula Novaes \\ Universidade Federal de Santa Catarina - UFSC - Brasil \\ Guilherme Arthur Possagnoli Freitas \\ Universidade Federal de Santa Catarina - UFSC - Brasil \\ Adriano Beiras \\ Universidade Federal de Santa Catarina - UFSC - Brasil
}

\section{RESUMO}

Este estudo consiste em um levantamento bibliográfico das principais produções sobre o tema de violência contra mulheres e a atenção ao autor de violência, de 2006 a 2016. Busca fornecer um panorama geral sobre a temática, além de avaliar carências e potenciais aspectos para pesquisa e intervenção com os homens autores de violência. Foram analisados 22 artigos que tratam da temática da violência doméstica e familiar contra as mulheres, com foco no homem autor de violência (HAV). Nestes são apontadas as justificativas usadas para a legitimação da violência contra suas parceiras, explicitando a necessidade da produção de novos modelos de masculinidades. O segundo aspecto tratado pelos artigos são reflexões, fruto da dinâmica dos grupos de trabalho com os HAV, sobre a violência conjugal. Nota-se que há uma grande lacuna na produção de estudos e políticas voltadas para os homens autores de violência no Brasil, ficando evidente na análise a necessidade de maior enfoque nesses homens. Onde já há grupos reflexivos para homens, ainda existe a ausência de políticas regulamentadoras e a existência de desafios práticos, como a falta de treinamento dos profissionais que lidam com os HAV.

Palavras-chave: Violência de Gênero; Violência contra Mulher; Homens Autores de Violência; Masculinidades; Gênero.

\section{INTRODUÇÃO}

A violência contra mulheres é uma violação dos direitos humanos e um empecilho à busca da igualdade de gênero em todo o mundo. É uma forma de violência que exemplifica o contexto de privilégio que existe na sociedade, na qual homens se utilizam de seu poder para dominar as mulheres, especialmente se esta for sua parceira em uma relação conjugal. É também uma das formas mais comuns de violência, sendo que $30 \%$ das mulheres do mundo que já estiveram dentro de um relacionamento sofreram alguma forma de violência física ou sexual perpetrada por seu parceiro (OMS, 2014). Isso tem resultado em uma crescente 
conscientização mundial, tornando inclusive, a igualdade de gênero, um dos principais objetivos da "Agenda 2030 para o Desenvolvimento Sustentável” da ONU, que pretende: "eliminar todas as formas de violência contra todas as mulheres e meninas nas esferas públicas e privadas, incluindo o tráfico e exploração sexual e de outros tipos "(ONU, 2015).

Segundo a Organização dos Estados Americanos (OEA) a violência de gênero é definida como "qualquer ato ou conduta baseada no gênero, que cause morte, dano ou sofrimento físico, sexual ou psicológico à mulher, tanto na esfera pública como na esfera privada" (OEA, 1994). No Brasil, o movimento feminista protagonizou a exigência por mudanças, resultando em maiores problematizações sobre o tema. Essa repercussão acarretou na regulamentação na esfera jurídica da violência de gênero, tendo como cume a Lei 11.340, Maria da Penha (LMP) Esta lei foi responsável por disseminar o debate sobre a violência conjugal para o resto da sociedade, propiciando uma grande leva de estudos e reflexões.

Porém a violência de gênero é um fenômeno multifacetado, que se forma no nível relacional e social, com seus fatores políticos e histórico-culturais. Ainda assim, grande parte das leis se voltam apenas à mulher, como realça Granja e Medrado (2009): “as políticas sociais e a legislação atual parecem não considerar a violência como parte dessa complexidade relacional. O foco continua sendo as mulheres, (...) reafirmando a distinção sexual em detrimento da ordem de gênero"(p.27).

Existe uma lacuna nos estudos sobre homens autores de violência (HAV), seus processos de socialização e concepções sobre a violência. Um conhecimento maior dos HAV pode auxiliar no entendimento da etiologia da violência e auxiliar na elaboração de políticas de enfrentamento. Compreender a complexidade da violência de gênero holisticamente pode reverberar em mudanças socioculturais e diminuir suas ocorrências. Por esse motivo, uma atenção especial direcionada ao homem tem sido realçada como essencial na busca pelo fim da violência contra a mulher. O tema é de grande relevância no cenário atual, inclusive está em tramitação no congresso um projeto de lei que altera a Lei Maria da Penha (LMP) para estabelecer medidas protetivas aos centros de educação e de reabilitação para os HAV.

Tendo isso em vista a passagem de dez anos da promulgação da LMP, o objetivo desse estudo é analisar as publicações científicas realizadas no período de 2006 a 2016 que tenham como foco o homem autor da violência contra mulheres. Além disso, pretende-se fornecer um panorama sobre o tema a partir dessas produções e sobre as características mais relevantes acerca da atenção ao homem autor de violência. 


\section{MÉTODO}

Este estudo caracteriza-se como uma revisão integrativa da literatura científica a partir da pergunta de pesquisa "O que tem sido produzido sobre a atenção aos Homens Autores de Violência entre 2006 e 2016?”. O ano de 2006 foi escolhido para início por ser simbólico no tema violência de gênero por tratar do ano de promulgação da Lei 11.340, conhecida como Maria da Penha. Esta lei tem sido um marco significativo para uma alavancagem nas discussões públicas sobre a violência de gênero e na propulsão das produções científicas sobre o tema. Escolhemos o período até 2016 para marcar os dez anos desta lei e refletir seus impactos, em especial sobre a recomendação de ações com homens autores de violência contra mulheres.

O levantamento bibliográfico foi realizado no Banco de Dados SciELO (Scientific Electronic Library Online) e o Banco de Teses da CAPES (Coordenação de Aperfeiçoamento de Pessoal de Nível Superior) durante os meses de junho de 2015 a março de 2016. A escolha do SciELO foi baseada em sua importância acadêmica, como uma das principais datas nacionais gratuitas. O banco de dados da CAPES, por sua vez é uma referência em publicações de teses de curso de pós-graduação. A seleção dos artigos foi realizada a partir da combinação dos descritores: "Violência", "Gênero", "Homem", "Violência Doméstica", “Autores", "Masculinidades" e "Agressor". Inicialmente foram selecionados 473 artigos, fruto da pesquisa com os descritores supracitados. Posteriormente foram excluídos artigos que não tratavam de HAV, grande parte por analisar apenas as mulheres em situação de violência. Alguns centravam-se em outras formas de violências, não interessando ao intuito deste estudo, restando cerca de 58 trabalhos.

Após uma análise mais detalhada dos resumos e de informações específicas, tais como a metodologia e foco das publicações houve uma nova triagem que culminou com um total de 22 artigos científicos que se enquadravam no propósito de analisar a produção acadêmica e fornecer um panorama geral sobre o tema proposto por esse estudo.

A apresentação dos dados está dividida em duas partes, sendo a primeira um mapeamento das publicações encontradas a partir do procedimento descrito e a segunda parte conta com uma apresentação sobre os aspectos principais referentes ao homem autor de violência encontrado na literatura analisada. Por se tratar de uma revisão de literatura, grande parte dos textos analisados são referidos constantemente no decorrer do texto. Para uma melhor compreensão e leitura mais fluida foi optado por representar os 22 textos analisados a partir de sua numeração contida na tabela 1. Os outros autores e autoras utilizados para 
complementar a revisão e que não estão na tabela citada, serão citados a partir do seu nome e data.

\section{RESULTADOS}

Nota-se que apesar da crescente literatura sobre o tema violência de gênero, ainda há muito pouco sendo produzido com o foco no HAV. Este fato é constatado pela discrepância entre o número de 473 artigos que falavam de violência contra a mulher em geral e de apenas de 22 que contemplavam o HAV nos seus estudos.

\section{Tabela 1. Dados gerais dos trabalhos selecionados}

\section{No REFERÊNCIA}

$1 \quad$ Alves; Pinto; Silveira; Oliveira; Melo

2

3 Cortez; Souza

4 Cortez; Souza; Queiróz

5 Deeke; Boing; Oliveira; Coelho

6 Falcke; Oliveira; Rosa; Bentancur

$7 \quad$ Gomes; Diniz; Camargo; Silva

8 Granja; Medrado

$9 \quad$ Griebler; Borges

10 Lima; Büchele; Clímaco

11 Lima; Büchele

12 Madureira; Raimondo; Ferraz; Empírico PR Marcovicz; Labronici; Mantovani

Empírico ES

Empírico SC

Teórico RS

Empírico

Empírico

Empírico

Teórico SC

Teorico SC

$\begin{array}{llllll}\text { Tipo de } & \text { Esta } & \text { Sexo do Escritor } & \text { Área } & \text { de } & \text { Ano de } \\ \text { Estudo } & \text { do } & \text { Principal } & \text { Publicação } & & \text { Publicação }\end{array}$

Empírico MG $\quad$ Fem $\quad$ Saúde Pública

Masc Psicologia

Fem

Saúde Pública

2009

Fem

Psicologia

2009

BA

Fem

Enfermagem

2012

PE

Fem

Psicologia

2009

RS

Fem

Psicologia

Masc

Saúde Publica

2008

Masc

Saúde Pública

2011

Barbarói, Santa Cruz do Sul, n.51, p.<154-176>, jan/jun, 2018 


\begin{tabular}{|c|c|c|c|c|c|c|}
\hline 13 & Medrado (Dantas); Méllo & Teorico & PE & Masc & Psicologia & 2008 \\
\hline 14 & Medrado; Lemos; Brasilino & Empírico & PE & Masc & Psicologia & 2011 \\
\hline 15 & Moraes; Ribeiro & Empírico & RJ & Fem & $\begin{array}{l}\text { Sexualidade e } \\
\text { Gênero }\end{array}$ & 2012 \\
\hline 16 & Natividade & Empírico & MG & Fem & $\begin{array}{l}\text { Estudos } \\
\text { Linguísticos }\end{array}$ & 2012 \\
\hline 17 & $\begin{array}{l}\text { Oliveira ; } \\
\text { Gomes }\end{array}$ & Teórico & $\mathrm{AM}$ & Fem & Saúde Pública & 2011 \\
\hline 18 & $\begin{array}{l}\text { Rosa; Boing; Büchele; Oliveira; } \\
\text { Coelho }\end{array}$ & Empírico & $\mathrm{SC}$ & Masc & Saúde Pública & 2008 \\
\hline 19 & M. Santos & Empírico & RJ & Fem & Serviço Social & 2012 \\
\hline 20 & N. Santos & Empírico & $\mathrm{RS}$ & Fem & Sociologia & 2012 \\
\hline 21 & Silva; Coelho; Njaine & Empírico & $\mathrm{SC}$ & Fem & Saúde Pública & 2014 \\
\hline 22 & Winck; Strey & $\begin{array}{l}\text { Empiríco } \\
\text { / Teórico }\end{array}$ & RS & Masc & Psicologia & 2007 \\
\hline
\end{tabular}

Fonte: Tabela elaborada pelos autores.

É importante ser destacado que grande parte dos artigos encontrados pertencem as áreas de Saúde Pública e Psicologia. Dos 22 textos utilizados, 7 deles pertencem a ordem da Saúde Pública, enquanto 9 deles foram publicados em revistas de Psicologia.

Apesar do grande território brasileiro, as pesquisas sobre o tema se concentram nos estados mais meridionais do país. Santa Catarina e Rio Grande do Sul constituem juntos a origem de cerca de metade dos estudos realizados sobre a temática desde 2006. As pesquisas provenientes de Santa Catarina são responsáveis por 6 das 22 publicações científicas. Enquanto Rio Grande do Sul contem 4 das publicações.

Ao observar o sexo dos autores é possível verificar um predomínio de autoras do sexo feminino nas publicações. Das 22 publicações 15 foram realizadas por mulheres, enquanto as outras 7 são de responsabilidade de homens. Os números se referem ao primeiro autor de cada produção científica. 
As publicações brasileiras concentram-se no campo empírico com o total de 15 trabalhos, seja através de entrevistas, análise documental ou participações em grupos focais ou reflexivos. Enquanto publicações teóricas contam com seis publicações, como revisões de literatura ou reflexões críticas. Um dos trabalhos analisados é uma tese que é a junção de três diferentes artigos, dois teóricos e um empírico, sendo considerado na análise como teórico/empírico.

Na tabela 2 há a explicitação de maiores detalhes das publicações, apresentando os focos e métodos utilizados em cada um dos 22 textos trabalhados.

\section{Tabela 2. Descrição dos estudos empíricos com Homens Autores de Violência}

$\mathbf{N}^{\mathbf{O}} \quad$ Foco

1 Compreender o envolvimento dos homens com a violência.

2 Contribuir com ferramentas de análise que permitam abrir novas perspectivas para a intervenção jurídica e assistencial.

3 Analisar as concepções e práticas de gênero de homens envolvidos em relacionamentos violentos.

4 Investigar como as relações estabelecidas entre casais em situação de violência são vivenciadas e descritas por eles e de que modo práticas e concepções de gênero dos casais se articulam na configuração dos episódios de violência.

5 Análise da dinâmica da violência doméstica a partir do discurso da mulher agredida e de seu parceiro autor da agressão.

\section{Método Utilizado}

Realização de trinta grupos focais

Analisar criticamente leis e políticas sobre violência de gênero.

Entrevista com quatro homens com histórico de violência conjugal em seus relacionamentos atuais e que foram denunciados na Delegacia de Defesa da Mulher (Deam) por agredirem fisicamente suas parceiras.

Entrevista semi-estruturada com quatro casais que possuíam histórico de violência na relação e que mantinham o relacionamento conjugal após denúncia de agressão física realizada pela mulher.

Entrevista com trinta casais cujas mulheres haviam registrado na Delegacia da Mulher de Florianópolis. 
Realizar uma reflexão sobre as possibilidades de atuação, preventiva e terapêutica, de psicólogos, terapeutas familiares e profissionais da saúde face à violência conjugal.

Identificar características socioeconômicas de mulheres e homens com história de violência conjugal.

Entender qual o lugar do atendimento aos homens autores de violência nos serviços voltados para a violência contra as mulheres.

9 Traçar um perfil dos homens envolvido em violência contra a mulher.

10 Reflexão sobre a incorporação dos homens e da perspectiva de gênero nos esforços de prevenção e atenção à violência contra as mulheres.

11 Desenvolver uma reflexão crítica sobre as intervenções com homens autores de violência doméstica e familiar contra mulheres.

12 Delinear o perfil de agressores detidos em flagrante delito e da violência que perpetraram contra mulheres.

13 Reflexões críticas e éticas sobre a atenção dada aos homens autores de violência nas diretrizes governamentais.

14 Analisar posicionamentos e argumentos construídos por profissionais que atuam na rede de enfrentamento à violência contra as mulheres acerca das possibilidades e modalidades de atenção aos homens denunciados.

15 Analisar os significados que os homens acusados
Realizar uma revisão crítica da literatura acerca dos conceitos de violência conjugal, violência de gênero e violência contra a mulher.

Entrevista estruturada sistemática com 50 mulheres e 50 homens com história de violência conjugal.

Entrevistas semiestruturadas com profissionais que atuam diretamente na rede de prevenção, assistência e enfrentamento da violência doméstica e familiar contra a mulher.

Análise de 103 boletins de violência em uma delegacia da Polícia Civil no Rio Grande do Sul no ano de 2010.

Análise de trabalhos que abordam os temas homens e violência contra as mulheres.

Revisão de literatura nacional e estrangeira sobre o tema.

Pesquisa retrospectiva documental, realizada mediante apreciação de 130 Autos de Prisão, analisados pela estatística descritiva.

Exercício teórico estudando a situação de homens que cometem violência contra mulheres.

Análise qualitativa das entrevistas feitas com profissionais que atuam em serviços diretamente relacionados à denúncia e acompanhamento de casos de violência de gênero.

Grupos de Reflexão para homens autores de 

contra as mulheres

16 Analisar o processo de produção de significados sobre as experiências pessoais de homens que exercem violência contra mulher a partir da moldura analítica da semiótica social e da multimodalidade.

17 Apontar pontos de discussão que ajudem a elucidar/reformular a problemática, bem como aspectos que ainda são obscuros ou negligenciados sobre o tema homens e violência conjugal.

18 Investigar as causas da agressão conjugal contra a mulher a partir da ótica do homem autor de violência

19 Identificar problemas na aplicação das medidas de atenção ao HAV prevista na Lei Maria da Penha.

20 Identificar a articulação entre os grupos reflexivos com as políticas públicas sobre a atenção ao homem autor de violência, além das mudanças provocadas nos participantes e mediadores desse grupo.

21 Investigar as motivações da violência conjugal segundo os depoimentos de homens e mulheres de violência atribuem às agressões perpetradas

violência em um Juizado de Violência Doméstica e Familiar contra a Mulher

Participação em grupos focais

Analisar qualitativamente 54 textos brasileiros sobre homens e violência conjugal, relacionados a atividades de pesquisa ou de intervenção.

\section{Participação em grupos focais}

Pesquisa exploratória de natureza qualitativa, junto aos profissionais que atuam em dois programas públicos que trabalham com HAV em Manaus.

Pesquisa de campo qualitativa a partir de entrevistas com integrantes das principais iniciativas de atenção ao HAV.

Análise das informações obtidas nos inquéritos sobre violência doméstica perpetrada pelo companheiro ou ex-companheiro e que continham o depoimento de casal realizada na Delegacia da Mulher

22 Tese contendo três artigos com focos em: legitimação social da violência; análise da percepção de violência para HAV e experiência prática em um grupo reflexivo.

Tese contendo três artigos com métodos de: revisão teórica a partir da experiência empírica da legitimação da violência conjugal; análise do discurso de HAV e relato participativo em um grupo reflexivo.

Fonte: Tabela elabora pelos autores. 
A tabela 2 reúne o foco de cada um dos estudos analisados, e sua respectiva metodologia. Apesar das diferenças idiossincráticas de cada produção cientifica, percebe-se que há certos enfoques usualmente mais investigados dentro do tema homem autor de violências. Com o intuito de melhor compreensão das temáticas pesquisadas, os artigos foram agrupados em três principais temas.

Há uma série de estudos que visam explicitar a dinâmica do homem com a violência, buscando compreender sua perspectiva de gênero e outras construções sociais. Em grande parte dos trabalhos com este enfoque, os autores optam por fazer uma análise a partir do discurso de homens que participam de grupos focais ou grupos de reflexão. Muitos também se utilizam de entrevistas com casais com histórico ou em estado de violência, ou meramente com o homem autor da violência.

Outra perspectiva de estudos procura identificar padrões motivacionais dado pelo homem para justificar sua violência. Ou detectar padrões socioeconômicos dos envolvidos em violência de gênero, inclusive buscando traçar um perfil do homem autor de violência, e sua cônjuge. Grande parte das produções com este enfoque escolhem se utilizar de uma metodologia pautada em questionários ou uma pesquisa retrospectiva documental. Podem inclusive analisar informações obtidas nos inquéritos e em entrevistas com envolvidos em violência de gênero.

O terceiro grande foco nas produções buscam fazer uma reflexão sobre leis, políticas públicas ou produções científicas sobre violência de gênero, com o enfoque no HAV. Visando fazer uma análise crítica sobre déficits jurídicos e investigando a incorporação de grupos reflexivos e iniciativas assistenciais nas diretrizes governamentais. Com esse propósito, os autores frequentemente realizam uma análise qualitativa de entrevistas feitas com profissionais que trabalham em serviços vinculados à denúncia e atenção à violência de gênero no país. Além de haver vários trabalhos que realizaram revisões críticas de produções científicas nacionais e internacionais que abordam os temas homens e violência contra as mulheres.

A seguir será feita uma análise qualitativa dos textos. Serão destrinchados alguns dos temas mais recorrentes, realizando uma reflexão sobre o lugar dos HAV na literatura científica brasileira.

\section{Análise qualitativa}

Após a leitura e análise das publicações selecionados e a apresentação de um mapa sobre as publicações acerca dos homens autores de violência entre os anos de 2006 a 2016 no 
Brasil, será fornecido um panorama geral para apresentar a temática. Para facilitar a apresentação e a compreensão, a exposição foi dividida em 5 tópicos: contextualização histórica; a importância da atenção ao HAV; motivos da violência; dificuldades dos trabalhos com os HAV; encaminhamentos futuros propostos.

O primeiro tópico, Contextualização Histórica, tem como foco explicitar ao leitor ou leitora qual foi o percurso histórico da atenção ao HAV nas últimas décadas. Percebe-se que essa contextualização é frequentemente retratada nos textos analisados, mesmo que de forma fragmentada. Este tópico proporciona uma noção da caminhada histórica que culmina no debate contemporâneo sobre a atenção aos homens autores de violência.

O segundo tópico se refere ao que a literatura relata sobre a importância dessa atenção ao HAV. São abordados apontamentos trazidos pelos autores para justificar e ilustrar a importância do trabalho com os homens. Além de apontar benefícios e resultados da intervenção com os autores de violência.

Os motivos da violência são trazidos no terceiro tópico da discussão. Exerce um ponto de destaque por ser um dos temas mais debatidos nos artigos estudados. São detalhadas algumas das principais constatações feitas pelos autores referenciados. Destaca-se que os motivos da violência não são meramente reduzíveis a uma equação causa-efeito, havendo diversas determinantes de ordem estrutural e social.

O quarto tópico traz à tona as principais dificuldades na implementação e realização dos trabalhos com homens autores de violência. Abarcam algumas das dificuldades vivenciadas e detectadas pelos pesquisadores e pesquisadoras na implementação da atenção ao HAV. Também apontam os principais empecilhos atuais na elaboração do atendimento, retratando pontos de ordem legislativa, socioculturais e relacionais.

O quinto e último tópico foca nos apontamentos existentes para a execução de serviços de atenção mais eficazes no futuro. A partir de reflexões e orientações presentes na literatura analisada são traçadas algumas sugestões sobre a temática do trabalho de homens autores de violência.

\section{Contextualização histórica}

De acordo com os dados obtidos da análise, mostra-se necessário uma introdução ao contexto histórico e político que circunscreveu o trabalho com os homens autores de violência. Os primeiros trabalhos com HAV datam da passagem da década de 1970 para 1980 na América do Norte, mais especificamente Canadá e Estados Unidos da América. As ações 
tinham como objetivo complementar a prevenção à violência contra a mulher e responsabilizar os autores da violência (11).

No Brasil a criação das Delegacias Especiais de Atendimento à Mulher (DEAMs), em 1985, foi um importante marco para o combate a violência contra mulheres. Criou-se um ambiente mais propício para aquelas que sentiam dificuldade em reportarem seus casos de violência em delegacias comuns de polícia. Essas delegacias, contudo, não contavam com qualquer forma de trabalho com os homens envolvidos nos casos de violência.

A partir da criação das DEAMs, o debate sobre a questão da violência contra a mulher passou a ganhar maior notoriedade. Um dos grandes debates que cercou o tema referiu-se à Lei 9.099 de 1995, que regulamentou a criação de Juizados Especiais Criminais (JECrim). Os JECrim são responsáveis pelo julgamento de infrações penais de menor potencial ofensivo e acabaram atendendo as demandas referentes à violência contra mulheres, minimizando assim a gravidade de tal violência. Esse embate culminou em 2006 na promulgação da Lei $\mathrm{N}^{\circ}$ 11.340 - mais conhecida como Lei Maria da Penha, para lidar especificamente com a violência conjugal, lei que completa 10 anos de vigência em 2016.

Apesar da íntima relação com a violência e a preconização do trabalho com os homens na Lei Maria da Penha, a inclusão dos homens autores de violência nas políticas contra a violência deu-se tardiamente se comparado à atenção dada a mulher. No Brasil, apenas na segunda metade da década 1990 algumas organizações não governamentais passaram a dar importância ao tema, mesmo que não estivesse em sua pauta principal, como é exemplo os Instituto Noos-RJ, Instituto Papai e Instituto Promundo. Essas instituições, entre outras e grupos de pesquisas de universidades, formam atualmente a RHEG - Rede de Homens pela Equidade de Gênero.

A partir da maior atenção ao homem na questão da violência conjugal, as iniciativas que trabalham com o homem passaram a gradativamente ganhar espaço na sociedade, resultando no trabalho específico com os homens autores de violência. Na esfera governamental, o Centro Especial de Orientação à Mulher (CEOM) de São Gonçalo/RJ, passou a promover atendimentos individuais e grupos reflexivos com enfoque de gênero para os HAV, a partir de 1999 (11). O CEOM de São Gonçalo trabalhava em parceria com o Noos mostrando o papel ainda preponderante de ONGs e contou com uma reincidência de $2 \%$ do HAV, enquanto a média nacional em locais sem atendimento ao homem é de $51 \%$ (19).

$\mathrm{Na}$ atenção aos homens autores de violência predominam os grupos reflexivos, há também os que adotam um caráter psicoeducativo. Os referenciais teóricos predominantes são a perspectiva sistêmica e o construcionismo social. A forma de encaminhamento dos homens 
às intervenções é majoritariamente compulsória, realizada pelo Judiciário e por outras instituições como delegacias, abrigos, conselhos; mas relata-se também grupos formado por homens voluntários $(17 ; 19,20)$.

O Instituto Noos antes de participar como parceiro do movimento de mulheres de São Gonçalo, iniciou em uma DEAM o mesmo trabalho de grupos reflexivos sobre violência e masculinidades com os HAV. Porém notou-se que as DEAMs não eram o lugar mais adequado para tal trabalho, pois poderia prejudicar o espaço de segurança e respeito necessário para as mulheres em situação de violência que lá frequentavam (BEIRAS, 2014).

O trabalho com os homens autores de Violência em centros de prevenção e reeducação já havia sido mencionado pela Lei Maria da Penha, mas sem maiores especificações aconteceu uma iniciativa em 2008, por meio da proposta para "Implementação de Responsabilização e Educação dos Agressores". Os centros serviriam para acompanhar as decisões judiciais referentes aos HAV, com modelos semelhantes ao grupo reflexivos já citados. Atualmente a maior parte dos grupos já foram absorvidos por instituições governamentais, como atesta o mapeamento nacional do Instituto NOOS (BEIRAS, 2015).

\section{A importância da atenção ao HAV}

Há diversas razões que fundamentam uma atenção direcionada ao homem. A vasta maioria dos artigos analisados abordam a participação dos HAV como essencial na busca pelo fim da violência de gênero. Essa visão é compartilhada por várias organizações, como a ONU, que em seu relatório de 2006 apontou o envolvimento proativo de homens como um dos principais norteadores na prevenção da violência contra a mulher. Inclusive, a atenção ao HAV é vista como uma condição pertinente para a melhor eficácia no atendimento à mulher vítima da violência (ONU, 2006). As iniciativas de atenções recentes destinadas as vítimas de violência tem se mostrado eficaz, gerando mudanças na vítima. Porém a violência é constituída relacionalmente e se o outro membro permanece igual, ele poderá encarar a mudança da vítima como uma afronta, e inclusive aumentar a reincidência da violência na relação. "Todos percebem que a vítima precisa de ajuda, mas poucos veem esta necessidade no agressor. As duas partes precisam de auxílio para promover uma verdadeira transformação da relação violenta”'(SAFFIOTI, 2004, p.68).

$\mathrm{O}$ atendimento ao HAV é um passo relevante na direção de buscar relações mais equitativas entre os gêneros, especialmente com o intuito de cessamento de quaisquer formas de violência, porém esse não é o único objetivo do trabalho com os homens. Diversos autores

retratam a importância da atenção no processo de responsabilização do homem pela sua 
violência e no seu desenvolvimento emocional $(2 ; 3 ; 10 ; 11 ; 14 ; 15 ; 17)$. A responsabilização é um dos processos mais árduos e ao mesmo tempo mais fundamentais nas dinâmicas, porque os trabalhos feitos com homem demonstram como muitas vezes eles possuem uma resistência para se verem como agressores $(3 ; 16 ; 21)$. Descrevendo sua ação como uma resposta ou uma punição necessária à sua cônjuge.

A responsabilização do homem acaba sendo um dos melhores mecanismos de grupo para alterar isso $(2 ; 3 ; 11 ; 14 ; 15 ; 16 ; 17)$. Ao dar a oportunidade para o homem refletir sobre seu papel no interior da família, possibilitam uma desnaturalização de determinadas atribuições de gênero hegemônicas. Isso os auxilia a desenvolver uma visão mais crítica de como esses atributos são socialmente construídos, possibilitando uma ressignificação de suas próprias relações de gênero, quebrando com a ótica da mulher "merecedora" da violência. O processo de responsabilização implicaria em o HAV se assumir como responsável pelo fim das agressões, estabelecendo novas formas de se relacionar dentro da dinâmica familiar. (15)

As ressignificações da violência são trabalhadas nos grupos de atenção com homens autores de violência, nos quais, por meio de dinâmicas. A violência é debatida em três principais focos: a influência das construções de gênero e masculinidade; a distinção entre relacionamentos íntimos saudáveis e não saudáveis, e formas não violentas de resolução de conflito (11)

Nos trabalhos feitos com os HAV, nota-se um padrão de emparelhamento da violência com a concepção do que é ser homem $(1 ; 2 ; 3 ; 4 ; 6 ; 10 ; 14 ; 15 ; 17 ; 21)$. Grande parte dos artigos analisados realçam a origem da violência como um comportamento almejado na construção das masculinidades. Para compreender melhor a dinâmica da violência de gênero se constrói como essencial um entendimento transversal das formas de significações e socializações a partir de masculinidades, onde a concepção cultural de ser homem está intrinsecamente relacionada com a repressão de suas emoções e a canalização de suas manifestações pessoais em forma de agressão e violência física (10). Essa ótica, porém, é usualmente deixada de lado nos estudos de gênero gerando os três "silêncios" relacionados aos homens e à violência, segundo Nascimento (2001): 1.a incapacidade de enxergar os homens como objeto de intervenção e análise; 2. o silenciamento e falta de reflexão em cima das construções da masculinidades sofre emoções e intimidade. 3. A construção cultural recorrente dos homens de resolver conflitos pela violência.

A construção das masculinidades, em especial uma masculinidade tradicional é fortemente pautada na posse e submissão da mulher, e quando essa "obediência" não é respeitada pela mulher, podem surgir problemas como o ciúmes. Este é visto como um 
afrontamento direto a virilidade masculina, e por isso é utilizado como justificativa pelos HAV para sua agressão $(3 ; 5 ; 21)$. As suspeitas de traição e os ciúmes são circunstâncias que muitos homens relatam como desencadeadores de um descontrole mental e emocional que acarretam na agressão (20). O ciúmes pode ser compreendido como uma das formas mais simbólicas para entender a masculinidade tradicional, por "legitimar" a violência quando há um "descumprimento" das atribuições de gênero pré-estabelecidas.

A socialização masculina, que ensina o homem a resolver seus conflitos de forma violenta, não só fere a sua cônjuge, mas também outras pessoas à sua volta e a si mesmo. Na construção de sua masculinidade, surge a violência como forma legítima de se relacionar no mundo. Ao provar a sua masculinidade pela força física, o homem também se torna mais vulnerável à diversos transtornos mentais e comportamentais (10), gerando altos índices de homicídio, suicídio, acidentes de trânsito e incidentes relacionados à diversas formas de violência (13). Diversos estudos também fazem o paralelo entre os valores associados à socialização masculina com o consumo de droga $(2 ; 15 ; 21)$.

Outro tópico recorrente nos textos mostra como muito dos HAV não são somente "ensinados" no âmbito macrossocial, mas também no micro, dentro do próprio núcleo familiar. No trabalho com HAV normalmente nota-se que durante a infância a violência era usualmente utilizada como meio de resolução de conflito. É possível realçar a importância da atenção ao homem, por esta proporcionar uma oportunidade ao HAV de localizar a violência em sua história de desenvolvimento $(6 ; 14)$.

Logo, uma atenção especial direcionada ao HAV pode dar a oportunidade de desnaturalizar a concepção da violência ser intrínseca ao homem, auxiliando na desconstrução de certas atribuições de gênero hegemônicas. Dando os subsídios para o homem encontrar melhores meios de resolver seus conflitos, tanto com a sua cônjuge, quanto em suas outras relações sociais.

\section{Motivos da violência}

As causas para a violência contra a mulher são discutidas em dois eixos principais. $\mathrm{O}$ primeiro eixo são as causas estruturais, em que os artigos debatem sobre o problema da violência na esfera social em que os sujeitos estão circunscritos. O segundo foca sua análise causal da violência em aspectos pessoais dos agressores, majoritariamente. Não se tratam de abordagens excludentes, mas pelo contrário, servem para uma apreensão mais ampla da temática. 
É necessário compreender a relação conjugal entre homens e mulheres inserida em uma determinada sociedade que é permeada por discursos de poder $(1,15,19,21)$. Esses discursos conferem diferentes status sociais aos cidadãos. Torna-se, portanto, inevitável voltar-se para o contexto social em busca de discursos que legitimem as práticas de violência entre os membros de uma relação.

No polo de causas estruturais, baseado no marco teórico de Hannah Arendt encontrase a discussão sobre a violência presente nas relações entre casais, em que a violência é fruto de relações desiguais de poder entre pessoas. As relações passam a se dar entre sujeitos e objetos e não mais entre dois sujeitos ativos e políticos. Violência resultando diretamente de relações desiguais, caracterizadas pela lógica do mando-obediência (1).

Relações desiguais como as entre os gêneros em nossa sociedade firmam-se em diversos dispositivos sociais, que naturalizam posições construídas pela própria sociedade, escondendo a artificialidade de determinadas posições. Uma dessas construções é o modelo de masculinidades contemporâneo. Dentre as diferentes masculinidades possíveis, há um padrão que emerge como hegemônico, que se ancora na heterossexualidade, racionalidade e violência $(3 ; 10 ; 13 ; 21)$.

A violência é, como se pode ver, um importante pilar da socialização masculina desde a infância, em um processo em que as demais emoções e sentimentos são reprimidos. (13, 17, 22). Esse modelo de socialização normativo acaba limitando a experiência do homem. Estimulando-o a expressar suas emoções apenas por vias agressivas, resultando em um importante aspecto na questão da violência, não apenas conjugal, permeando grande parte das relações masculinas.

A partir da naturalização da violência masculina, os homens passam a ver a violência como algo comum e não se julgam agressores na maior parte dos casos de violência doméstica $(3 ; 11 ; 15 ; 17 ; ; 18 ; 21)$. Essa desresponsabilização é uma das fundamentais barreiras a ser quebrada no trabalho com homens autores de violência (11).

Já no polo das variáveis pessoais na violência conjugal, os estudos pautam-se em entrevistas ou experiências em grupos reflexivos. Procurando a partir do discurso dos homens qual a gênese da violência, aparecem o álcool, insegurança na relação e questionamento da autoridade masculina como os maiores responsáveis pela violência.

O primeiro trabalho no polo de variáveis pessoais é baseado em entrevistas com os HAV. As motivações da violência no discurso dos homens nesse estudo estão divididas em três eixos: Ela, Eu e Outros. Na categoria "Ela" fica clara essa fuga da responsabilidade pela violência, justificando-a por disputas de poder na relação, falta de cuidado com os filhos e 
autodefesa. Na categoria "Eu", a causa é colocada fora do sujeito, em problemas com álcool ou socioeconômicos. Já na "Outros" o que se revela é a interferência de terceiros na relação, mais uma vez colocando causas externas ao sujeito (11).

Outro interessante estudo contribui para uma compreensão mais detalhada do assunto a partir da introdução do conceito de "account", desenvolvido pelo interacionista Erving Goffman. O conceito é dividido em duas categorias: desculpas e justificações. Essas ocorrem quando alguém aceita a responsabilidade perante o ato, mas nega o fato dele ser inapropriado, enquanto que aquelas se diferenciam por haver consciência inapropriação do ato, mas há também a negação da responsabilidade por ele. Durante seus estudos os pesquisadores encontraram tanto desculpas quanto justificações no discurso dos homens autores de violência. As justificações foram traição; falta de respeito; ciúmes e desconfiança; falta de cuidado com os filhos. Enquanto as desculpas se baseiam no consumo de álcool e na força física maior do homem (15).

Por último, uma análise detalhada nos artigos pesquisados revela que a entrada maciça das mulheres no mercado de trabalho tem sido destacada como um dos motivos geradores de violência conjugal. A conquista de espaço é muitas vezes interpretada como uma ameaça à figura de autoridade masculina, desencadeando insegurança e sofrimento aos homens, que apelam para a violência em uma tentativa de reconstituir seu espaço de domínio $(1 ; 4 ; 6 ; 7$; $10 ; 15 ; 17 ; 22)$. Esse último fator é visto nas motivações pessoais dos HAV, mas também se configura como um fator social importante.

\section{Dificuldade de trabalho com os HAV}

Após compreender melhor o contexto histórico, a importância do trabalho com os homens e a dinâmica motivacional apresentada em casos de violência, é importante compreender porque o trabalho com os homens autores de violência ainda encontra dificuldades na implementação nacional.

A lei 11.340, conhecida como lei Maria da Penha, foi um grande marco no combate à violência doméstica, criando uma especificidade para esse tipo de crime, deixando de ser considerado um crime de menor potencial ofensivo. A lei também foi um marco para o trabalho com os autores de violência, já que em seus artigos 35 e 45, ela pontua a necessidade de um trabalho de prevenção e reeducação com eles.

Promulgada em 2006, a lei aproxima-se de seus 10 anos e apesar dos avanços que ela permitiu, hoje alguns pontos ganham importância para um debate da situação da violência conjugal. Em relação ao atendimento aos HAV a Lei Maria da Penha apresenta duas lacunas, 
a primeira é a não explicitação de um trabalho de promoção de saúde junto à população masculina, a segunda é que não há nenhuma especificação sobre a organização dos centros de atendimento dos "agressores" $(2 ; 13)$.

Além disso, a lei apresenta ainda uma lógica de estigmatização do homem "agressor" e da mulher "ofendida", expressões presentes 34 e 19 vezes, respectivamente. Repetições essas que não contribuem para a superação dos binómios entre homem e mulher, excluindo a dimensão relacional das interações de gênero $(2 ; 3 ; 4 ; 6 ; 14 ; 17 ; 19)$.

O encaminhamento dos homens autores de violência para os trabalhos de grupos também é precário, devido a falta de uma política mais específica sobre o tema. O SUS mostra problemas na alocação dos encaminhamentos dos HAVs. Cabendo ao CAPS-AD, por exemplo, o trabalho com esses homens, gerando reforçadores de estigmas e uma dificuldade no trabalho direcionado para a violência conjugal $(2 ; 8)$.

Os empecilhos para esse trabalho não se restringem ao campo teórico. A leitura dos artigos selecionados evidenciou o despreparo dos profissionais que trabalham nessa área. Muitos não recebem o preparo necessário para lidar com o autor de violência. Pela falta de iniciativa pública a formação dos profissionais fica a cargo, muitas vezes, de organizações não governamentais $(2 ; 15 ; 16)$.

Em outro artigo, trata-se sobre as diferentes visões dos profissionais que trabalham com HAV sobre o tema da violência conjugal. Dentro dessa diversidade encontra-se as visões essencialistas que não fogem da lógica de fixação de agressores - homens e vítimas mulheres, que contribuem para a estigmatização e naturalização da prática da violência entre os gêneros $(7 ; 14)$. É possível observar a concordância dos profissionais com a punição ao tratar o HAV, na qual grande parte dos profissionais compreende a prisão como sendo a melhor forma de lidar com os "agressores". E a reeducação é tratada como uma medida punitiva complementar, e não um direito para a sua reeducação de gênero $(2 ; 14)$.

Dentro dos grupos de trabalho com homens que visam a reflexão e a criação de novos sentidos perante a violência, há alguns problemas a serem combatidos. O primeiro é a alta rotatividade dos participantes $(11,15)$. Em pesquisa feita em um grupo que trabalha com homens autores de violência aponta que a alta rotatividade parece ser fruto da falta de costume dos homens em se engajarem nesse tipo de tratamento (11).

A falta de motivação dos homens para frequentar o grupo perpassa pela visão que eles têm sobre os programas. Pelo pouco tempo de implantação o trabalho com homens ainda enfrenta alguns preconceitos sociais na academia, população e dos próprios participantes. Mesmo dentro dos HAV, há uma visão estigmatizada deste trabalho como uma forma de 
punição ao ato de violência cometida, o que dificulta a realização de um trabalho mais consistente $(2 ; 8 ; 15)$.

Para finalizar as complicações, a responsabilização do homem pelo seu próprio ato de violência é um dos principais objetivos dos grupos reflexivos de HAV. As dificuldades citadas anteriormente culminam em uma grande dificuldade de responsabilizar esses homens autores de violência, que acabam usando "accounts" e transferindo a responsabilidade pelo ato para causas externas, ambientais ou de sua parceira $(2 ; 3 ; 10 ; 11 ; 14 ; 15 ; 17)$.

\section{Encaminhamentos futuros}

Analisando os artigos escolhidos percebe-se que a pesquisa e intervenção com o trabalho de atenção a homens ainda é recente no Brasil, tendo como precursor o trabalho feito por ONGs (15). Em grande parte dos relatos feitos pelas instituições que o realiza, nota-se que há efeitos positivos, mesmo que modestos $(10,11)$. Vale pontuar que há poucos estudos longitudinais sobre os efeitos dos grupos reflexivos no Brasil. Um dos poucos estudos de São Gonçalo, como já citado, registrou taxas de reincidência de apenas 2\% (19).

Porém ainda há falta de sincronia e regulamentação do setor público para uma melhor eficiência e trabalho em rede, que poderia estar mais especificada na lei Maria da Penha ou em políticas públicas específicas. A crescente literatura científica nos últimos anos, que começa a colocar luz nos HAV, poderá servir como um norte na elaboração dessas leis $(1 ; 3$; $4 ; 5 ; 6)$.

Pontua-se, por exemplo, a necessidade de uma integralidade entre os setores públicos, criando uma maior comunicação entre o jurídico, segurança pública (delegacias, IML) e o sistema de saúde, além de uma maior articulação entre os próprios serviços de saúde. Porém nessa tentativa de estruturar uma rede eficaz, é necessário que o setor de saúde possa exercer a função de porta de entrada pros casos de violência de gênero, oferecendo uma atenção biopsicossocial. Assim ultrapassando a visão patologizante que atende esse crime pautado a partir da identificação de um dano físico, e não levando em conta toda sua complexidade. Ao transcender a ótica da violência dos homens como sendo uma doença, auxiliará na reformulação da maneira como os HAV enxergam o próprio sistema de saúde.

Porém, os serviços disponíveis não devem se prender meramente à ordem da saúde, o Estado deve agir na forma de proporcionar espaços para a reflexão acerca das construções de gênero. $\mathrm{O}$ trabalho de reeducação com o HAV lhes possibilita resignificar seu papel dentro da família, dando oportunidades de criar outras formas de masculinidades. Essa iniciativa também deve ser tomada de forma preventiva, e não só após a manifestação do ato de 
violência, proporcionando ambientes para que a comunidade tenha um contato maior com as discussões de gênero.

Para conseguir realizar uma atenção digna com os HAV, é necessário que os profissionais envolvidos tenham as habilidades e experiências suficientes para saber lidar com a complexidade do atendimento. Almejando esse desenvolvimento do repertório técnico, o Estado deve providenciar espaços de capacitações com materiais didáticos de qualidade aos profissionais, possivelmente buscando o suplemento de ONGs com experiências prévias na área.

É importante lembrar, porém, que não se deve meramente importar os modelos de intervenção já existentes em outros países, há de existir uma reformulação levando em conta a especificidade do homem e as influências socioeconômicas e culturais que lhe intersectam. Os serviços realizados com os HAV devem ser constantemente avaliados e reavaliados na busca de ofertar uma atenção de qualidade $(10,11)$.

\section{CONSIDERAÇÕES FINAIS}

A violência de gênero é um tema complexo. É importante superar as dicotomias homem/ mulher, agressor/vítima e enxergar a violência conjugal como fenômeno relacional, ficando evidente a necessidade de trabalhar com ambos os lados da relação. Porém ainda se encontra um baixo número de trabalhos que focalizam o homem autor de violência, tanto acadêmicos, como provou-se neste artigo, quanto práticos, 25 nacionalmente (BEIRAS, 2014). Todavia esta revisão mostrou algumas convergências nos estudos, como a importância do trabalho com o homem, a dificuldade de responsabilização dele e a violência, como fenômeno não limitado a um grupo social específico. Destaca-se o fato de que os estudos partem do pressuposto de que a atenção a apenas uma das partes da violência não tem tido resultado para o fim dela. Assim, não parecem justas as críticas de que a atenção aos HAV desvia foco e verba de atendimento as mulheres, asserção que acaba minando novas possibilidades de luta pelo fim da violência conjugal.

A intenção do artigo não foi esgotar as publicações nesta área, já que apenas duas bases brasileiras foram analisadas, mas antes fornecer um panorama geral dos estudos na área. Pela abrangência e transdisciplinaridade do tema alguns textos podem não ter sido identificados com os descritores usados. O intuito, porém, é que este artigo possa servir de base para ampliação dos estudos na área e familiarização com o tema.

Espera-se que estas ampliações possam suprir lacunas encontradas nos estudos de homens autores de violência. Neste sentido vale ressaltar que existem poucos estudos que 
discutam e expliquem metodologias de intervenção com os HAV e seus resultados. Estudos longitudinais na área também são outra carência. Para finalizar seria interessante futuros trabalhos que discutissem mais a fundo a construções de masculinidades, para além do episódio violento e como esta construção fundamenta práticas violentas entre casais.

\title{
THE BRAZILIAN SCIENTIFIC PRODUCTION OF MEN PERPETRATORS OF VIOLENCE - REFLECTIONS FROM A LITERATURE CRITICAL REVIEW
}

\begin{abstract}
This study consists of a literature review of academic productions regarding violence against women and the attention to the author of violence, from 2006 to 2016. It seeks to provide an overview on the subject, in addition to assessing needs and potential aspects for research and intervention with men perpetrators of violence against women. 22 articles were analyzed dealing with the issue of domestic violence against women, focusing on the man author of violence. In the content of these articles are identified the justifications used to legitimize violence against their partners, explaining the need for the production of new models of masculinity. The second aspect dealt by these articles are some reflexions on the dynamics of existing work groups with men who have used violence against women. Note that there is a big gap on the production of studies and policies focused on men who have used violence in Brazil, becoming evident in the analysis the need for greater regarding on these men. And where there are already existing reflexive groups for men, there are still a lack of regulatory policies and the existence of practical challenges, such as lack of training of professionals who work with these men.
\end{abstract}

Keywords: Gender Violence; Violence against women; Men Violence Authors; masculinities; Gender.

\section{RESUMEN}

Este estudio consiste en una revisión bibliográfica de las principales producciones sobre el tema de la violencia contra mujeres y la atención al autor de violencia, de 2006 hasta atención al autor de violencia, de 2006 até marzo de 2016. Tiene la intención de proponer un panorama general sobre el tema, evaluar faltas y aspectos potenciales para investigación e intervención con hombres autores de violencia. Han sido analizados 22 artículos que tratan del tema de la violencia doméstica y familiar contra las mujeres, direccionando para hombres autores de violencia. Son apuntadas las justificativas usadas para la legitimación de la violencia contra sus compañeras, explicitando la necesidad de producción de nuevos modelos de masculinidades. El segundo aspecto tratado en los artículos son reflexiones derivadas de la dinámica de los grupos de trabajo con los HAV, sobre violencia conyugal. Es posible notar que hay una gran falta de producción de estudios y políticas dirigidas a hombres autores de violencia en Brasil, tornándose evidente en el análisis la necesidad de mayor enfoque en los hombres. Donde ya hay grupos reflexivos para hombres, aún existe la ausencia de políticas con lineamientos y la existencia de desafíos prácticos, como la falta de capacitación de los profesionales que trabajan con los HAV.

Palabras clave: Violencia de Genero; Violencia contra Mujer; Hombres Autores de Violencia; Masculinidades; Género. 


\section{REFERÊNCIAS}

ACOSTA, Daniele Ferreira et al . Violência contra a mulher por parceiro íntimo: (in)visibilidade do problema. Texto contexto - enferm., Florianópolis , v. 24, n. 1, p. 121-127, Mar. 2015

ALVES, Rejane Aparecida et al . Homens, vítimas e autores de violência: a corrosão do espaço público e a perda da condição humana. Interface (Botucatu), Botucatu , v. 16, n. 43, p. 871-883, Dec. 2012

BEIRAS, Adriano. Relatório mapeamento de serviços de atenção grupal a homens autores de violência contra mulheres no contexto brasileiro. Instituto NOOS e Instituto Promundo. Rio de Janeiro, 2014. Disponivel em: http://noos.org.br/portal/wpcontent/uploads/2015/04/Relatorio-Mapeamento-SHAV_site.pdf

CONVENÇÃO INTERAMERICANA para prevenir, punir e erradicar a violência contra a mulher - Convenção de Belém do Pará, 1994.

DANTAS, Benedito Medrado; MELLO, Ricardo Pimentel. Posicionamentos críticos e éticos sobre a violência contra as mulheres. Psicol. Soc., Porto Alegre, v. 20, n. spe, p. 78-86, 2008 .

DEEKE, Leila Platt et al . A dinâmica da violência doméstica: uma análise a partir dos discursos da mulher agredida e de seu parceiro. Saude soc., São Paulo , v. 18, n. 2, p. 248258, June 2009 .

GRANJA, Edna; MEDRADO, Benedito. Homens, violência de gênero e atenção integral em saúde. Psicol. Soc., Florianópolis, v. 21, n. 1, p. 25-34, Apr. 2009.

LIMA, Daniel Costa; BUCHELE, Fátima; CLIMACO, Danilo de Assis. Homens, gênero e violência contra a mulher. Saude soc., São Paulo, v. 17, n. 2, p. 69-81, June 2008 .

LIMA, Daniel Costa; BUCHELE, Fátima. Revisão crítica sobre o atendimento a homens autores de violência doméstica e familiar contra as mulheres. Physis, Rio de Janeiro , v. 21, n. 2, p. 721-743, 2011

MADUREIRA, Alexandra Bittencourt et al . Perfil de homens autores de violência contra mulheres detidos em flagrante: contribuições para o enfrentamento. Esc. Anna Nery, Rio de Janeiro, v. 18, n. 4, p. 600-606, Dec. 2014.

MEDRADO, Benedito; LEMOS, Anna Renata; BRASILINO, Jullyane. Violência de gênero: paradoxos na atenção a homens. Psicol. estud., Maringá, v. 16, n. 3, p. 471-478, Sept. 2011 
MORAES, Aparecida Fonseca; RIBEIRO, Letícia. As políticas de combate à violência contra a mulher no Brasil e a "responsabilização" dos "homens autores de violência".Sex., Salud Soc. (Rio J.), Rio de Janeiro, n. 11, p. 37-58, Aug. 2012 .

NATIVIDADE, Claudia Felipe. Semióticas da(s) masculinidade(s) em um grupo de homens que exercem violência contra as mulheres. 2012. 179p. Tese (Doutorado em Estudos Linguísticos) - Universidade Federal de Minas Gerais, Belo Horizonte, 2012.

ORGANIZAÇÃO DAS NAÇÕES UNIDAS. Agenda 2030 para o Desenvolvimento Sustentável. New York, 2015 Disponível em: https://nacoesunidas.org/pos2015/agenda2030/ ORGANIZAÇÃO DAS NAÇÕES UNIDAS. In-depth study on all forms of violence against women. New $2006 . \quad$ Dork, em: http://www.un.org/womenwatch/daw/vaw/SGstudyvaw.htm

ROSA, Antonio Gomes da et al . A violência conjugal contra a mulher a partir da ótica do homem autor da violência. Saude soc., São Paulo, v. 17, n. 3, p. 152-160, Sept. 2008

SAFFIOTI, H. Gênero, patriarcado, violência. São Paulo: Fundação Perseu Abramo, 2004.

SANTOS, Milena do Carmo Cunha dos. Eu ser um homem feminino não fere meu lado masculino: percepções e socializações nos grupos reflexivos de gênero para homens autores de violência. 2012. 124p. Tese (Mestrado em Sociologia) - Universidade Federal do Rio Grande do Sul, Porto Alegre, 2012.

SANTOS, Nereyda Cardoso Muniz de Oliveira. Homens autores de violência doméstica e familiar contra mulher na cidade de manaus no contexto da lei maria da penha. 2011. 151p. Dissertação (Mestrado em Serviço Social) - Pontifícia Universidade Católica Do Rio De Janeiro, Rio de Janeiro, 2011.

SILVA, Anne Caroline Luz Grüdtner da; COELHO, Elza Berger Salema; NJAINE, Kathie. Violência conjugal: as controvérsias no relato dos parceiros íntimos em inquéritos policiais. Ciênc. saúde coletiva, Rio de Janeiro, v. 19, n. 4, p. 1255-1262, Apr. 2014.

WINCK, Gustavo Espíndula. Percepções sobre violência e relações de gênero em homens acusados de agressão. 2007. 102p. Dissertação (Mestrado em Psicologia) - Pontifícia Universidade Católica Do Rio Grande Do Sul, Porto Alegre, 2007.

\section{Sobre os autores}

Rodrigo Caio de Padula Novaes é graduadondo em Psicologia pela Universidade Federal de Santa Catarina (UFSC). Bolsista de Iniciação Científica Jovens Talentos (CAPES). Endereço eletrônico: rcpnovaes@gmail.com 
Guilherme Arthur Possagnoli Freitas é graduado em Psicologia pela Universidade Federal de Santa Catarina (UFSC). Bolsista de Iniciação Científica Jovens Talentos (CAPES). Endereço eletrônico: guiarthur@ hotmail.com

Adriano Beiras é Professor Adjunto do Departamento de Psicologia da Universidade Federal de Santa Catarina (UFSC). Professor do Programa de Pós-graduação em Psicologia da UFSC. Doutor Europeu em Psicologia Social (UAB - España), Becas MAEC-AECID. Estágios de Pós-doutorado (UFSC bolsa PDJ - CNPq, Universidad de Granada -UGr-España, University of Brighton-UK). Pesquisador (Margens-UFSC, Brasil, VIPAT-UAB, España). Endereço eletrônico: adrianobe@gmail.com 